\title{
Effect of Jackfruit Seed Starch (Artocarpus heterophyllus) Microstructure on Properties and Characteristics of Fried Battered Product
}

\author{
Rossaporn JIAMJARIYATAM \\ Department of Home Economics, Faculty of Science, Srinakharinwirot University, Bangkok 10110, Thailand
}

(Corresponding author's e-mail: rossaporn@g.swu.ac.th)

Received: 7 January 2017, Revised: 4 September 2017, Accepted: 18 October 2017

\begin{abstract}
The objective of this research was to study the effect of the ratio between wheat flour (WF) and jackfruit seed starch (JS) on the physical, chemical quality and sensory characteristics of batter coating. The ratio of WF to JS used in the study to make batter coating were 100:0, 90:10, 80:20, 70:30, 60:40, 50:50, 40:60, 30:70, 20:80, 10:90 and 0:100. The WF and JS exhibited the "A-type" crystal form. Increasing JS content in the starch mixture was found to increase amylose content and relative crystallinity significantly. The amount of oil absorption in the battered product decreased significantly with increasing amylose content. The microstructure of the batter coating differed significantly depending on the ratio of WF to JS from 100: 0, 80: 20, 60: 40, 40:60, 20: 80 and 0: 100. Higher JS content in the batter provided greater homogeneity with a fine starch network and less porosity. In terms of sensory descriptive analysis, adding JS resulted in increased hardness and crispness, but significantly decreased brittleness, puffiness, oiliness and oil coating $(p \leq 0.05)$. It was found that the highest acceptance levels of batter used the ratio of WF to JS of 50:50 which obtained the highest score in appearance, color, taste, flavor, texture and overall preference.
\end{abstract}

Keywords: Jackfruit seed starch (JS), amylose content, batter coating product, sensory attributes, consumer acceptance

\section{Introduction}

Jackfruit (Artocarpus heterophyllus) is a widely cultivated tropical fruit [1]. Of the jackfruit's fruit weight, $8-15 \%$ is accounted for by the seed [2]. Jackfruit by-products can be used in various valueadded products. For instance, the seeds are a major source of carbohydrate having a $60-80 \%$ starch by dry basis [3] while containing many phytonutrients. Jackfruit seed starch is widely used in many manufactured food products as it provides a gelling property which is suitable for various baked products $[4,5]$.

Batter coatings are made of flours mixed with other ingredients and used to dip food in before frying to achieve a crispy texture. Frozen batter is one of the value added products that has high market value in the food industry in which there is an increasingly high demand for healthy foods, which contain low fat and high dietary fiber content. Consequently, the food industry is interested in the development of a batter coating that has low oil absorption properties without detracting from favorable batter characteristics [6]. One interesting method to reduce oil absorption is to use high-amylose flour/starch to prevent oil penetration during frying.

Amylose content is the most important factor influencing product characteristics of starch. Despite this, there is little information on the relationship between the product characteristics and amylose content of jackfruit seed starches (JS). Instant batter coating products have become very popular given their convenience, especially in frozen form [7]. The main ingredients in preparation of batter coating products 
are wheat flour or rice flour. Different types and compositions of flour contribute to the variety in texture and puffiness of coating products, in particular, lightness, fragility, and denseness. In general, consumers prefer a crispy coating which is actually an indirect effect of oil absorption during the frying process [8]. Due to the fact that jackfruit seed starch (JS) contains in the range of 12 - $28 \%$ [9], it has a high level of amylose $(26-38 \%)[10,11]$ which makes it suitable for batter coating products. The high amylose starch reduces oil absorption and makes fried products crispy [8]. As indicated in the literature, many value added products are derived from jackfruit seed which is normally discarded after consumption of the fruit. Consequently, this research focuses on the use of jackfruit seed starch to produce healthy batter coatings for fried products. One of the desirable qualities of the gel from the jackfruit seed starch is that it is highly stable when frozen [12] and does not experience syneresis when kept at $4{ }^{\circ} \mathrm{C}$ for 5 days [13].

Deep-frying is the most common process used in the preparation of foods. The rapid escape of moisture during the frying process generates porosity in its structure allowing oil to penetrate the outer surface [14-16]. Today's health conscious consumers have concerns about oil absorption and content of fried products. Thus, the kind of flour or starch used is a critical factor in batter composition. Wheat flour (WF) creates structure and provides viscosity while cereal flours develop crispness [17]. Rice flour is often used in batter since it is an alternative providing fewer calories [18] and has a reduced level of oil absorption compared to wheat flour [19,20].

The effect of different cereal flours used as a batter for fried products has been investigated in a number of studies [20-23]. As starch gelatinization and protein denaturation occur during the frying process $[24,25]$, different starch types with a variety of microstructural features such as amylose content and relative crystallinity will have different influences on product characteristics. A common method of investigation of the microstructure of fried battered products is by scanning electron microscopy (SEM) analysis which is crucial in understanding the effects of frying [26-28]. A batter coating can be defined as a liquid mixture containing wheat flour and water. The product is dipped into batter before frying [6] to form a crisp crust which improves the unique flavor and texture of food products [29]. As there is a lack of research about the effects of wheat flour and JS in batter formulations on the microstructure resulting from deep-frying of battered products, this study aimed to investigate the effects of starch structure, such as amylose content and crystallinity, on batter coating characteristics.

Descriptive analysis for sensory evaluation is useful in providing details of sensory characteristics and to compare attributes of food products. Furthermore, descriptive analysis can be used as a tool in product development to analyze how well the developed product meets the needs of a target group, or to measure its suitability as a prototype product. Additionally, sensory analysis is used to compare the relationship between data from objective instruments and panels. It can also reveal sensory characteristics in the product to identify factors and ingredients that impact the sensory qualities that may gain consumer acceptance of each product. Therefore, descriptive analysis is necessary to develop batter coatings from JS that are both good for health and popular among consumers, and to forecast sensory characteristics that will meet consumer demands in other products.

For this research, it is hypothesized that the high amylose content of JS can reduce the oil absorption of fried products. The objectives of this study were to develop a batter coating product from JS, and to find the relationship between amylose content of JS and product characteristics that consumers will accept. Therefore, the study's aims are to:

1) Study the effects of amylose content and crystallinity on the characteristics of battered products.

2) Study the relationship between sensory characteristics/acceptance and starch properties in order to predict product acceptance.

\section{Materials and methods}

\section{Extraction of jackfruit seed starch}

The jackfruit seeds were dried in a hot air oven $\left(60{ }^{\circ} \mathrm{C}\right)$ for $2 \mathrm{~h}$. The extraction of JS was accomplished with modified method used in previous research [2,30,31]. A mixture of 1:3 seed to water ratio was ground and filtered through 200 mesh sieves. The filtrates were precipitated overnight at $4{ }^{\circ} \mathrm{C}$ by suspension in $0.5 \% \mathrm{NaOH}$. The supernatant was discarded and the crude starch was suspended in a 
http://wjst.wu.ac.th

0.5 M solution of sodium thiosulfate for $36 \mathrm{~h}$ after which the supernatant was drained. The dark-yellow sediment was then scraped. The white sediment was neutralized with $1.0 \mathrm{M}$ hydrochloric acid to $\mathrm{pH} 7.0$ and repeated 3 times before drying at $50{ }^{\circ} \mathrm{C}$ for $24 \mathrm{~h}$ in a hot air oven. The starch was finally ground and packed in an aluminum foil bag and kept at room temperature for further analysis. The moisture content of JS was found to be $9.05 \mathrm{~g} / 100 \mathrm{~g}$ dry basis.

\section{Starch yield}

Yield was calculated in percentage by calculating the difference between the initial weight and final weight per initial weight.

\section{Proximate analysis}

Moisture, crude protein, total lipid, ash, crude fibre and carbohydrate content were analyzed using AOAC (2005) [32].

\section{Starch mixture preparation}

The ratio between WF and JS was varied at 100:0, 90:10, 80:20, 70:30, 60:40, 50:50, 40:60, 30:70, 20:80, 10:90 and 0:100. The starch mixture contained $11.27 \pm 0.15 \%$ moisture and was kept at $4{ }^{\circ} \mathrm{C}$ for further analysis.

\section{Amylose content}

The amylose content of starch mixtures was quantified using the amperometric method [8].

\section{Crystal analysis}

The types and amount of crystallinity of the starch mixture were investigated using an X-ray Diffractometer (XRD). Wide-angle X-ray diffractograms were obtained using $\mathrm{CuK}_{\alpha}$ radiation of 0.154 $\mathrm{nm}$ and scanning from 4 to $40^{\circ}(2 \theta)$ at a rate of $4^{\circ} / \mathrm{min}$ [33]. Each sample was measured in triplicate.

\section{Batter coating preparation}

For batter preparation, the ratio of water to starch mixture was $1: 1$. The batter formulation was composed of a mixture of $90 \%$ starch, $5 \%$ sodium bicarbonate and $5 \%$ salt. To obtain the battered product, the starch mixture in 11 ratios was suspended by mixing with $50 \%$ water content. A $0.5 \times 0.5 \times 2$ $\mathrm{cm}^{3}$ carrot was then dipped into the batter to form a coating. The coating pickup measured by percentage between the difference in the weight of the carrot and the weight of the coated carrot per weight of carrot was found to be $23-37 \%$. The battered product was frozen in liquid nitrogen for 10 seconds and then stored at $-18^{\circ} \mathrm{C}$ for 7 days for further evaluation.

\section{Frying}

The frozen battered product was fried in rice bran oil at $110{ }^{\circ} \mathrm{C}$ for 5 seconds. The battered product samples were stored in a plastic box at room temperature for further evaluation.

\section{Oil absorption of battered product}

The rate of oil absorption was analyzed using Soxhlet's method according to the AOAC [34].

\section{Microstructure of battered product}

The battered product was frozen at $-50{ }^{\circ} \mathrm{C}$ for $48 \mathrm{~h}$. An evaluation of the lipid content was then carried out on the samples using hexane before investigation. The surface and cross section of the battered coating was illustrated using a SEM (JEOL: JSM-5800LV; Jeol Ltd., Tokyo, Japan). 


\section{Descriptive sensory analysis}

Ten students in the Department of Home Economics at Srinakharinwirot University in Bangkok, Thailand were screened to be panelist evaluators. A 15-point intensity scale was used to describe the batter's attributes. The panel was trained in the use of appropriate vocabulary for approximately $36 \mathrm{~h}$ for the sensory evaluation. Commercial products from markets were selected to refer to the textural mouth feel of the batter. Six battered products were evaluated in terms of attributes including hardness, crispness, brittleness, puffiness, oiliness, and oil coating with a 15-point numerical scale with anchored references. The evaluation process took about $20 \mathrm{~h}$.

\section{Acceptance test}

The evaluation of product preferences was done by thirty students of the Faculty of Science in Srinakharinwirot University. Eleven test samples prepared with random 3-digit number codes were presented in a white dish. Battered products were evaluated for preference according to appearance and texture using a 7-point hedonic scales $(1=$ not like at all to $7=$ like very much).

\section{Relationship between amylose content and consumer acceptance}

The relationship between the amylose content of the starch and its sensory attributes was determined in order to predict consumer acceptance.

\section{Statistical analysis}

All measurements were done in replicate. Statistical analysis was conducted on a completely randomized design with the analysis of variance (ANOVA). Duncan's new multiple range test was used to compare the difference means at the significance level of $p<0.05$.

\section{Results and discussion}

\section{Jackfruit seed starch yield}

The yield of jackfruit seed starch was $55.95 \%$. However, the jackfruit seed starch yield from previous research varied from between 12 - $28 \%[9,11,35]$. This was due to the application of different isolation methods in previous studies.

\section{Proximate analysis of jackfruit seed starch}

Jackfruit seed starch had a low protein $(0.08 \pm 0.01 \mathrm{~g} / 100 \mathrm{~g} \mathrm{db})$, ash $(0.03 \pm 0.01 \mathrm{~g} / 100 \mathrm{~g} \mathrm{db})$ and lipid $(0.03 \pm 0.01 \mathrm{~g} / 100 \mathrm{~g} \mathrm{db})$ content while the fibre and carbohydrate content were $0.21+0.01 \mathrm{~g} / 100 \mathrm{~g} \mathrm{db}$ and $99.57 \pm 0.21 \mathrm{~g} / 100 \mathrm{~g} \mathrm{db}$. The values were close to previous research $[2,3]$.

\section{Amylose content}

The amylose contents observed in the starch mixture with ratios of WF to JS of 100:0, 90:10, 80:20, $70: 30,60: 40,50: 50,40: 60,30: 70,20: 80,10: 90$ and 0:100 was between $26-41 \%$ (Figure 1a). The amylose content of JS in this research was higher than the amylose content of WF and JS found in other studies. This is in line with the finding of amylose content of JS from previous reviews which ranged from $22-38 \%$ depending on the isolation method and agricultural region $[2,9,11,12]$. However, the amylose content found in jackfruit seed starch is comparatively higher than that in the starch from wheat $[17,19,20]$. 

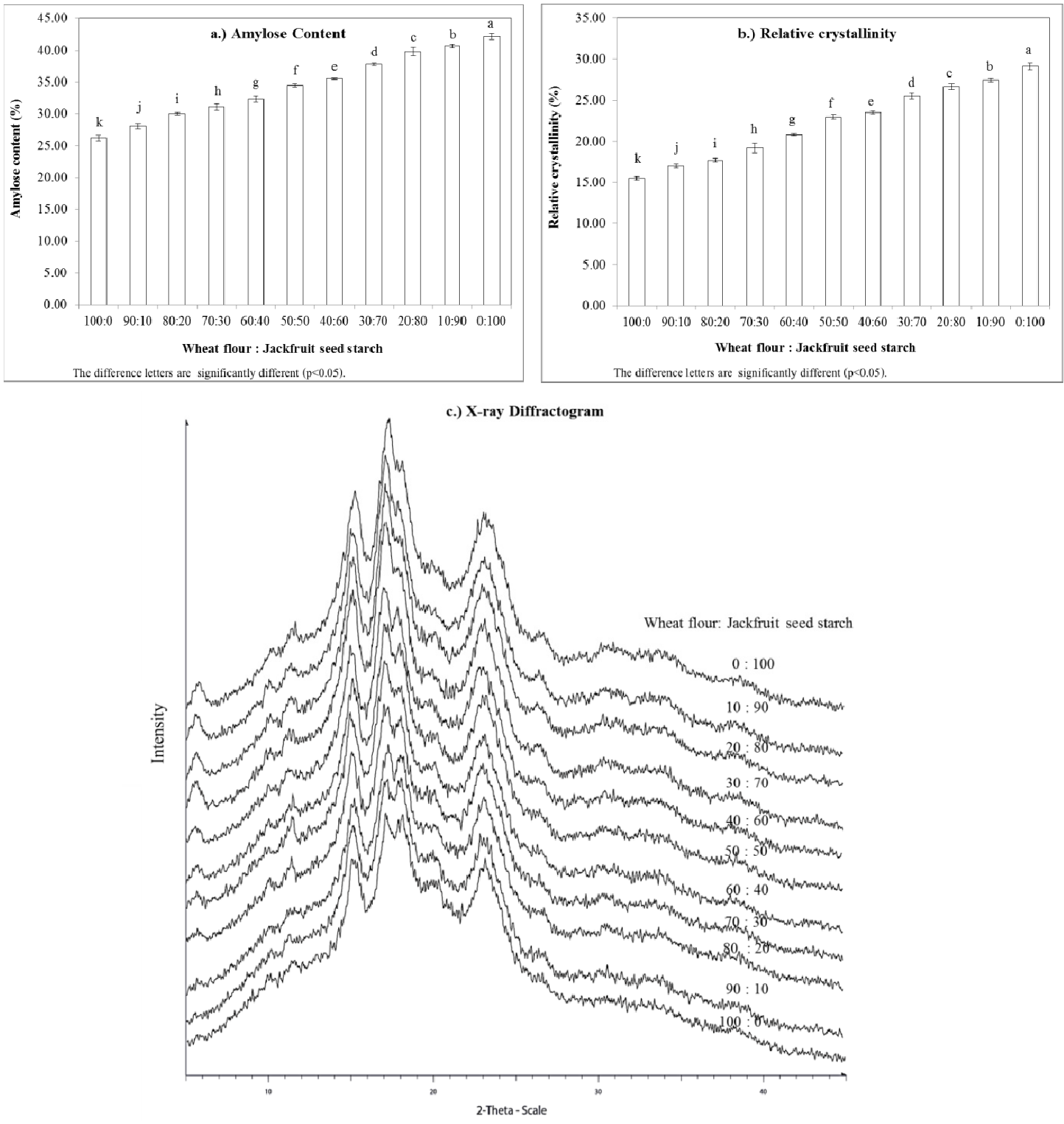

Figure 1 Amylose content (a), relative crystallinity (b), and crystalline type (c) of starch mixtures from wheat flour and Jackfruit seed starch.

\section{Crystal properties}

JS and WF illustrate A-type crystallinity with diffraction peaks at $2 \theta$ of $15,17,18$ and $23^{\circ}$ similar to cereal starch [36] which conforms to amylopectin double helices in close packing [37,38]. However, the crystalline form of the starch mixture shows A-type crystallinity (Figure 1c). This was due to the wheat flour being a cereal starch which corresponds to A-type crystallinity.

The relative crystallinity of jackfruit seed starches and starch mixtures are exhibited in Figure 1b. The relative crystallinity of WF and JS was found to be 16 and $27 \%$, respectively. Increasing JS in the starch mixture increased the relative crystallinity significantly. 
http://wjst.wu.ac.th

The findings on relative crystallinity in many studies show that JS crystallinity varies from 28 - 35 $\%[11,39]$. X-ray diffractograms were used to observe characteristics of crystalline structures of starch granules including the XRD pattern and the crystalline content. As shown in Figure 1c, the jackfruit seed starches exhibited strong diffraction peaks at $15.1,17.9$ and $23.0^{\circ}$. These diffractions were recognized as an A-type crystallinity pattern which corresponds to a close packing of amylopectin double helices as described by Gao et al. [37] and Zhang et al. [38]. Dutta et al. [12] studied the crystal structure of starch from jackfruit seed with X-ray diffraction, demonstrating that the jackfruit seed starch had type-A crystallinity pattern with peak angles at 15,18 and $23^{\circ}(2 \theta)$ respectively. This is similar to the study by Rengsutthi and Charoenrein [2], which showed that the jackfruit seed starch had a type-A crystallinity pattern, with peak angles at $15,17,17.9$ and $23^{\circ}(2 \theta)$ respectively and $28.42 \%$ crystallinity.

\section{The oil content of batter coating}

The differences in oil content of the 11 battered product $(\mathrm{p} \leq 0.05)$ are shown in Figure 2. Batter containing a ratio of WF to JS of 100: 0 had the most oil content (34\%). Increasing the JS ratio significantly decreased oil content $(\mathrm{p} \leq 0.05)$. Thus, batter with a ratio of WF to JS of 0:100 resulted in the least oil content $(16 \%)$. This result suggests that the oil content of a battered product depends on its amylose content and the relative crystallinity in JS. The amylose in starch granules forms a strong network resisting oil uptake from the outside. Moreover, an amylopectin increased the crystallinity resulting in high relative crystallinity of the starch batter. Therefore, the interactions between amylose and crystalline took place [8].

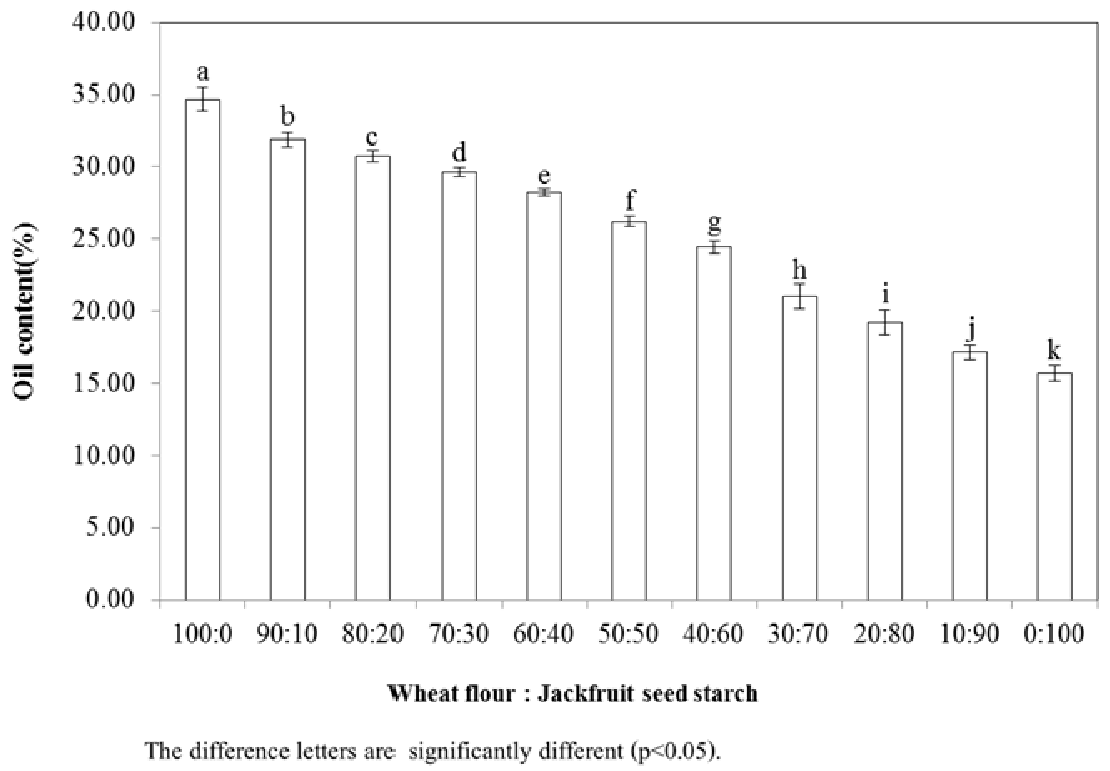

Figure 2 Oil content of battered product from starch mixture.

The correlation between amylose content and relative crystallinity of JS and the degree of oil absorption of a battered product showed significant variation $(p \leq 0.05)$ as shown in Figure 3. Increasing amylose content and relative crystallinity decreased the oil absorption capacity of the batter coating. This is due to JS being high in amylose content and relative crystallinity in which the strong network has high water retention capacity causing less moisture loss which has the effect of reducing oil uptake during the deep frying process [40]. The swelling ability and solubility of JS is promoted when water temperature 
increases. The swelling and absorption of water is due to hydrogen-bond interactions beginning at free amylose chains which allow the entry of water molecules leading to the swelling of starch. Jackfruit seed starch has the ability to bind both water and oil, with percentages of 200 and $90 \%$ respectively. This type of starch, therefore, is widely used in the food industry [13].
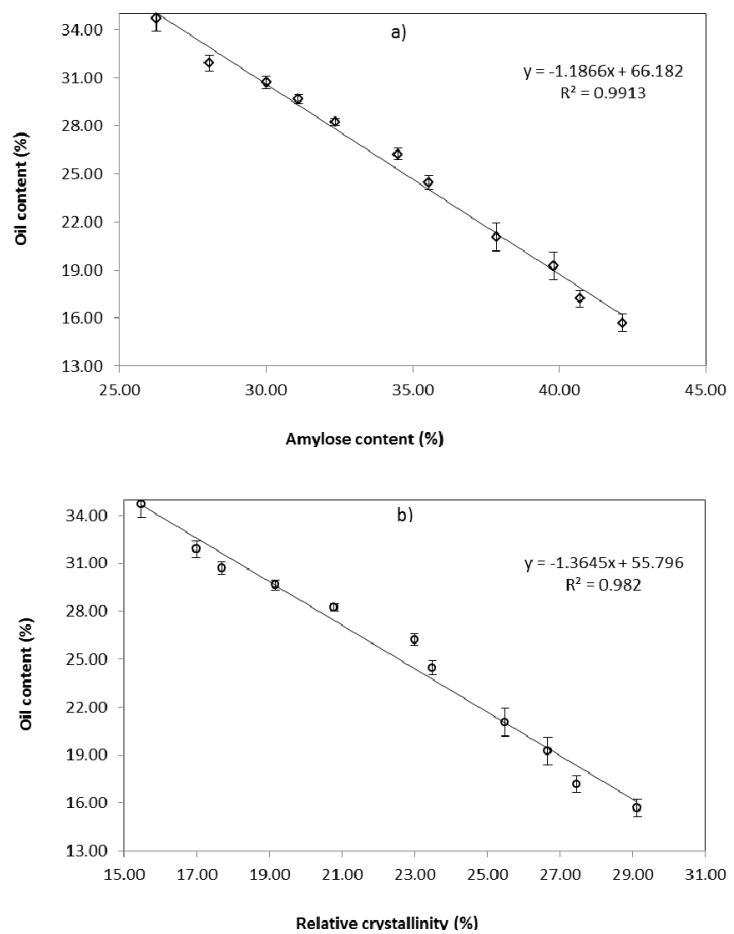

Figure 3 Correlation between amylose content and oil content (a) and relative crystallinity and oil content (b).

\section{Microstructure of batter coating}

Figure 4 shows structural changes as affected by JS content in the surface and cross-sections of the batter using a SEM. The higher content jackfruit seed starch batter coating is less porous, while the lowest JS content batter is observed to be more porous. Air cells inside the high JS content batter were smaller in size and fewer in number compared to the batter with low JS content. Increasing the quantity of JS caused the batter to become more finely porous in structure with more homogenous air cell walls. Thus, it is believed the JS content may contribute to the difference in the structural integrity of cells in the batter. The amylose forms a strong network causing less vaporization during frying. In contrast, a low amylose starch exhibits more steam escape providing large air cells [8].

For the mechanism of final fried products, the starch components (amylose and amylopectin chain) of JS and WF leached out of the granule. The WF and JS amylose was interconnected in their batter. The large starch granules as WF swelled at lower temperature and completed swelling earlier than smaller ones in JS. The final fried batter which the starch granules are gelatinized and gas cells can also be distinguished allowing oil transport through the product $[8,41]$. 


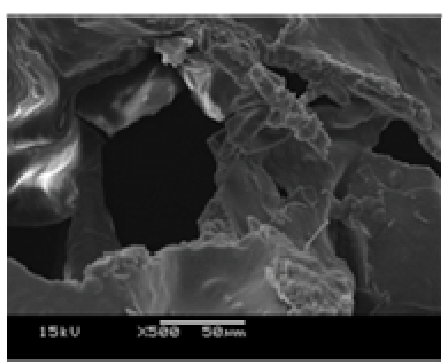

100: 0

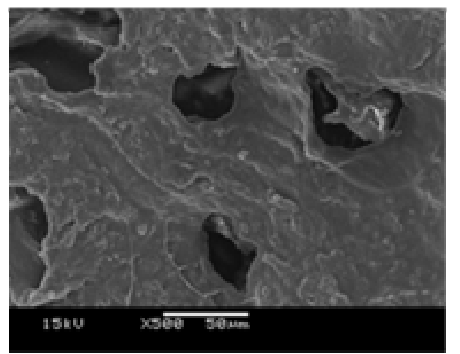

40: 60

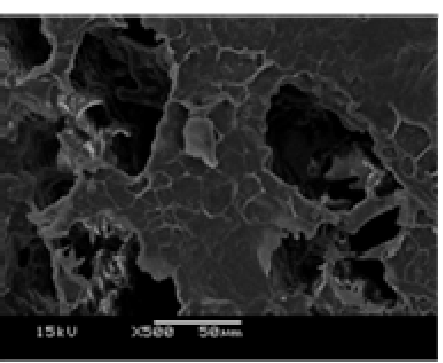

80: 20

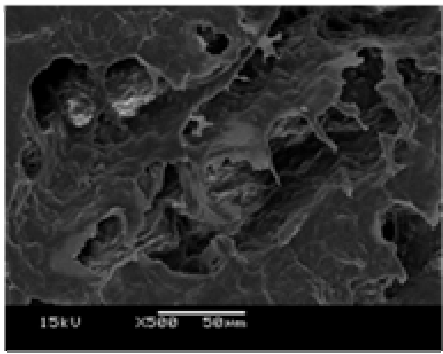

20: 80

(a)

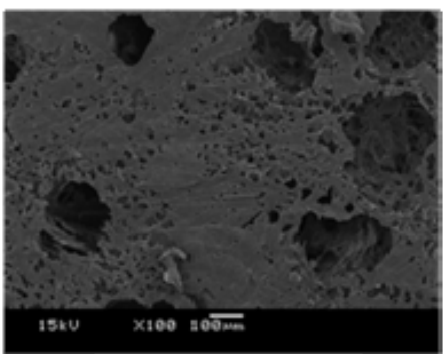

80: 20

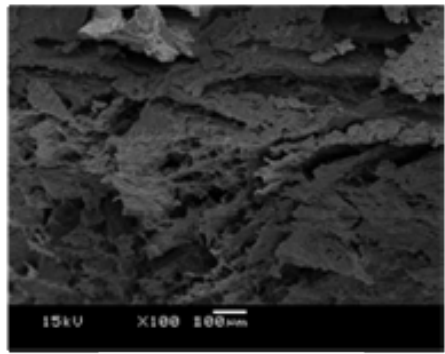

20: 80

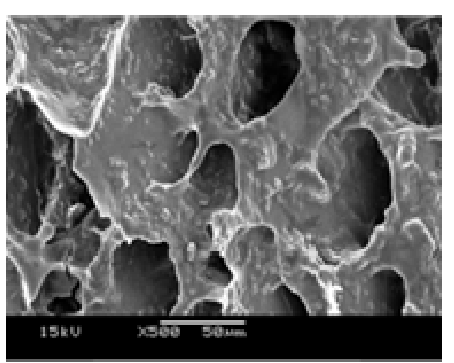

60: 40

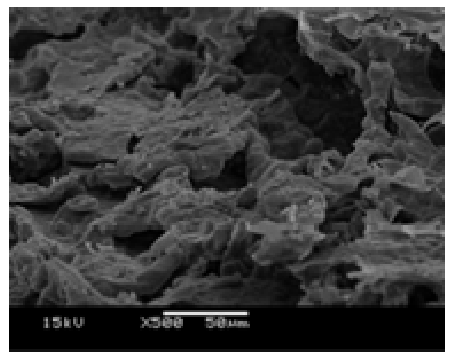

0: 100

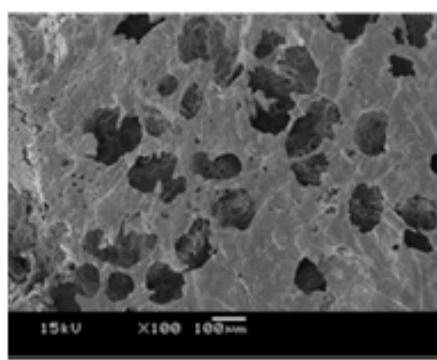

100: 0

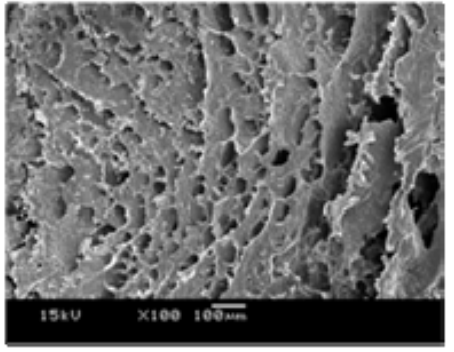

40: 60

(b)

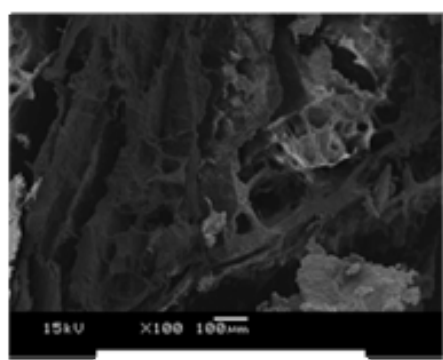

60: 40

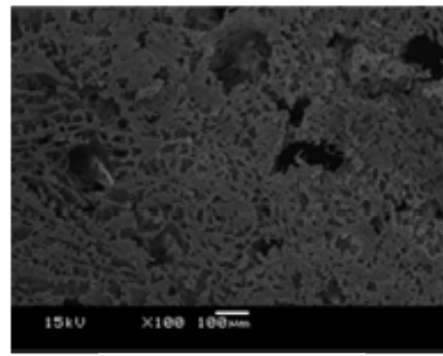

$0: 100$

Figure 4 Surface (a) and cross-section (b) of batter coating with varying ratio of wheat flour: jackfruit seed starch. 


\section{Descriptive sensory analysis}

The intensity of organoleptic characteristics of battered products containing ratios of WF to JS of 100:0, 80:20, 60:40, 40:60, 20:80, and 0:100 is shown in Figure 5a. The 6 different ratios of starch elicited significant $(\mathrm{p} \leq 0.05)$ differences in intensity scores in terms of hardness, crispness, brittleness, puffiness, oiliness and oil coating. Increasing content of JS was accompanied by an increase in hardness and crispness but significantly $(\mathrm{p} \leq 0.05)$ decreased brittleness, puffiness, oiliness and oil coating.

Descriptive sensory evaluation is a scientific method that measures, analyzes and interprets human sensations relating to quantitative and qualitative sensory characteristics of substances. Sensory evaluation is a method commonly used to evaluate sensory qualities of foods. The food industry currently uses sensory evaluation to develop more reliable methods to determine consumer preferences. Descriptive sensory analysis is one of the most comprehensive tools in sensory analysis and panelists must be intensively trained before testing. Moreover, this method determines which sensory characteristics influence product acceptance. Thus, descriptive sensory analysis is a type of analytical test utilizing people as a tool.

In terms of the sensory quality of the battered products, it was found that adding more JS increased hardness and crispness but decreased puffiness. It is believed that amylose content led to the formation of a stable gel. Complete gelatinization results in rigid starch interaction. A strong network of dried starch can resist the high vapor pressure which occurs inside during the frying process [8]. As a result, batters with higher JS content showed poor puffiness and less brittleness. These batters tended to be harder as well. From SEM observation, the batter appearance displayed fine air cells and high porosity. However, the degree of oiliness was found to decrease with increasing JS content. The strong network from the high content of amylose starch prevented oil penetration during frying. Similarly, Jiamjariyatam et al. [8] reported that increasing amylose content from 0.12 to $19 \%$ in pellets decreased oil absorption of a puffed product.

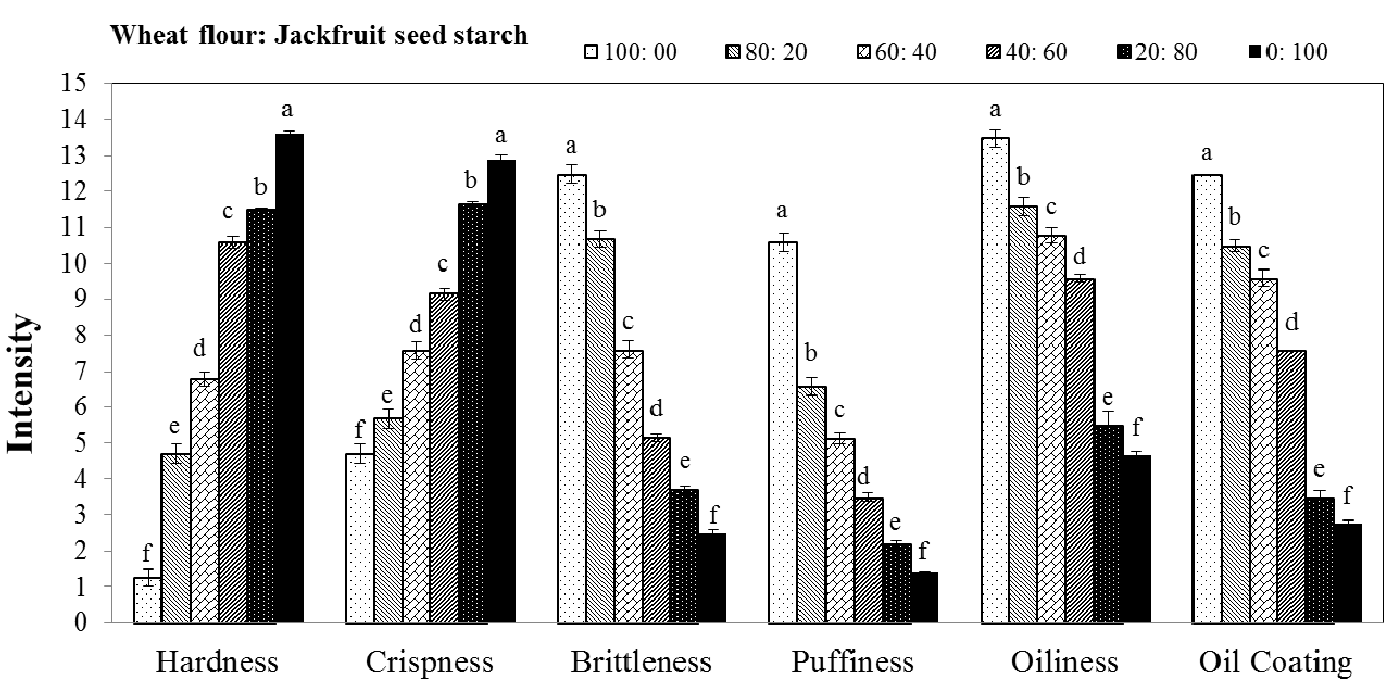

The difference letters are significantly different $(\mathrm{p}<0.05)$.

Figure 5 Intensity of sensory characteristics of battered product from starch mixture. 


\section{Acceptance}

Significant differences $(\mathrm{p} \leq 0.05)$ were found in the sensory acceptance of the 11 battered products according to preference in terms of appearance, color, flavor, taste, texture and overall liking as shown in Figure 6. Batter made with a ratio of WF to JS of 50:50 provided the highest score in all attributes at the scalar level of "like slightly - like very much" (5.0 - 5.5). Batters containing a ratio of WF to JS equal to 0:100 had a minimum preference score at the level of "do not like". Increasing the ratio of WF:JS to 100:0, 90:10, 80:20, 70:30, 60:40 and 50:50 created no significant difference in appearance, color, flavor, taste, and overall acceptance. However, increasing the ratio of WF to JS up to 50:50 decreased the preference score significantly $(\mathrm{p} \leq 0.05)$. The addition of JS to the batter resulted in poor puffiness and a very dark color in the final product with a hard texture. Moreover, the optimal JS content batter had a unique flavor thus affecting acceptance. It was found that the overall acceptance of the final product decreased with increasing JS content but the ratio of WF to JS of 50:50 in batters tested showed the greatest consumer acceptance. In terms of the relationship between amylose content and consumer acceptance, as seen in Figure 7, increasing amylose content tended to decrease the acceptance in appearance, color, and flavor.

a) Appearance

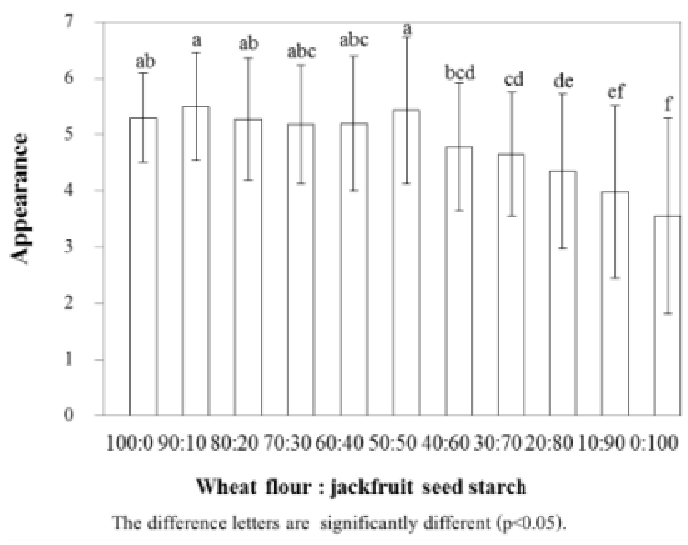

c) Flavor

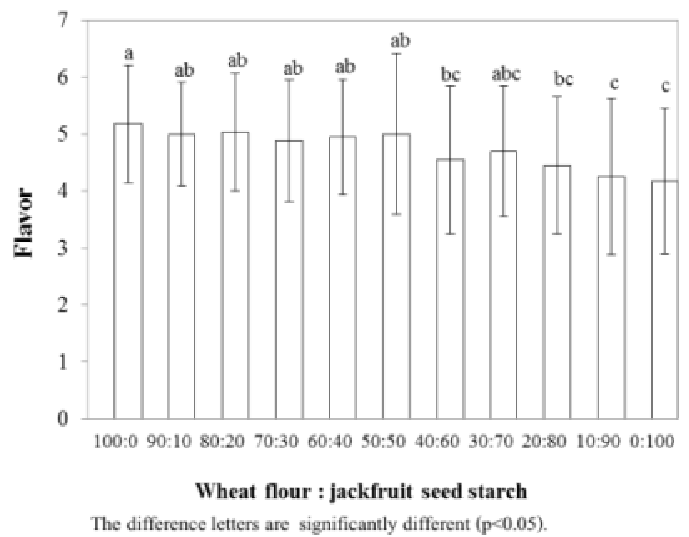

b) Color

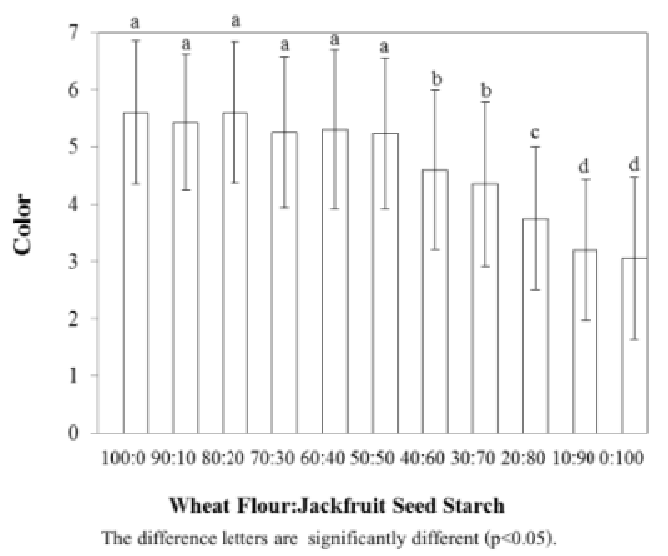

d) Taste

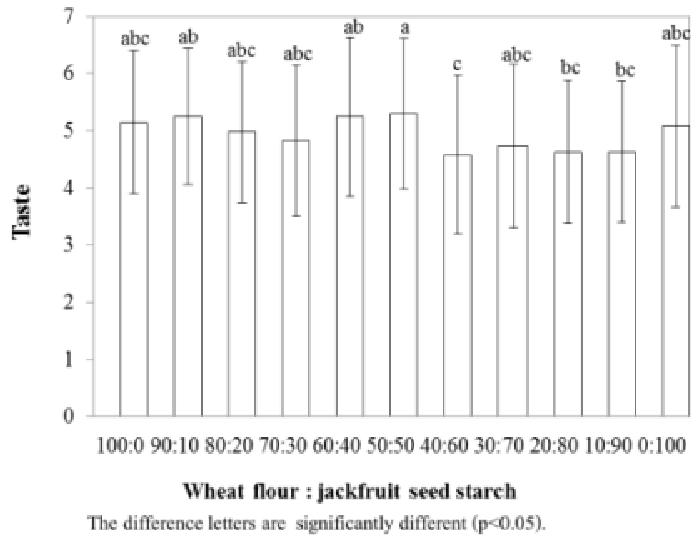


e) Texture

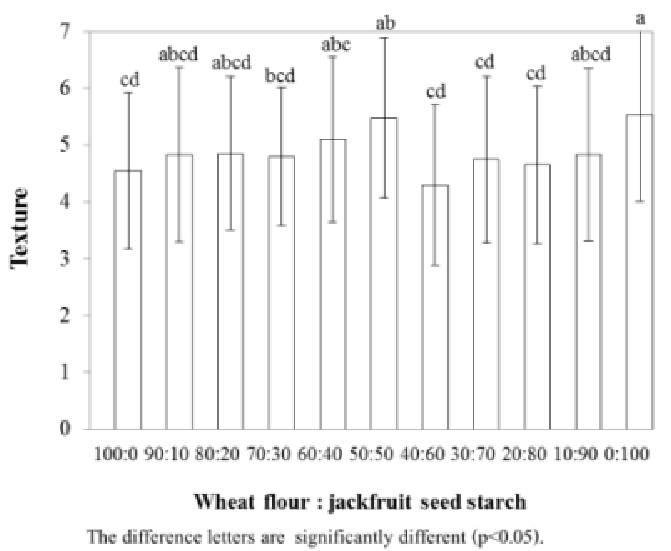

f) Overall

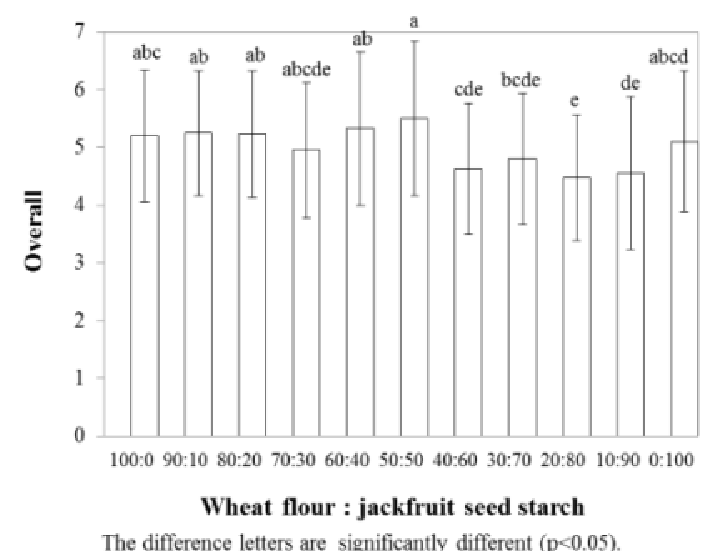

Figure 6 Preference score of battered product from starch mixture.
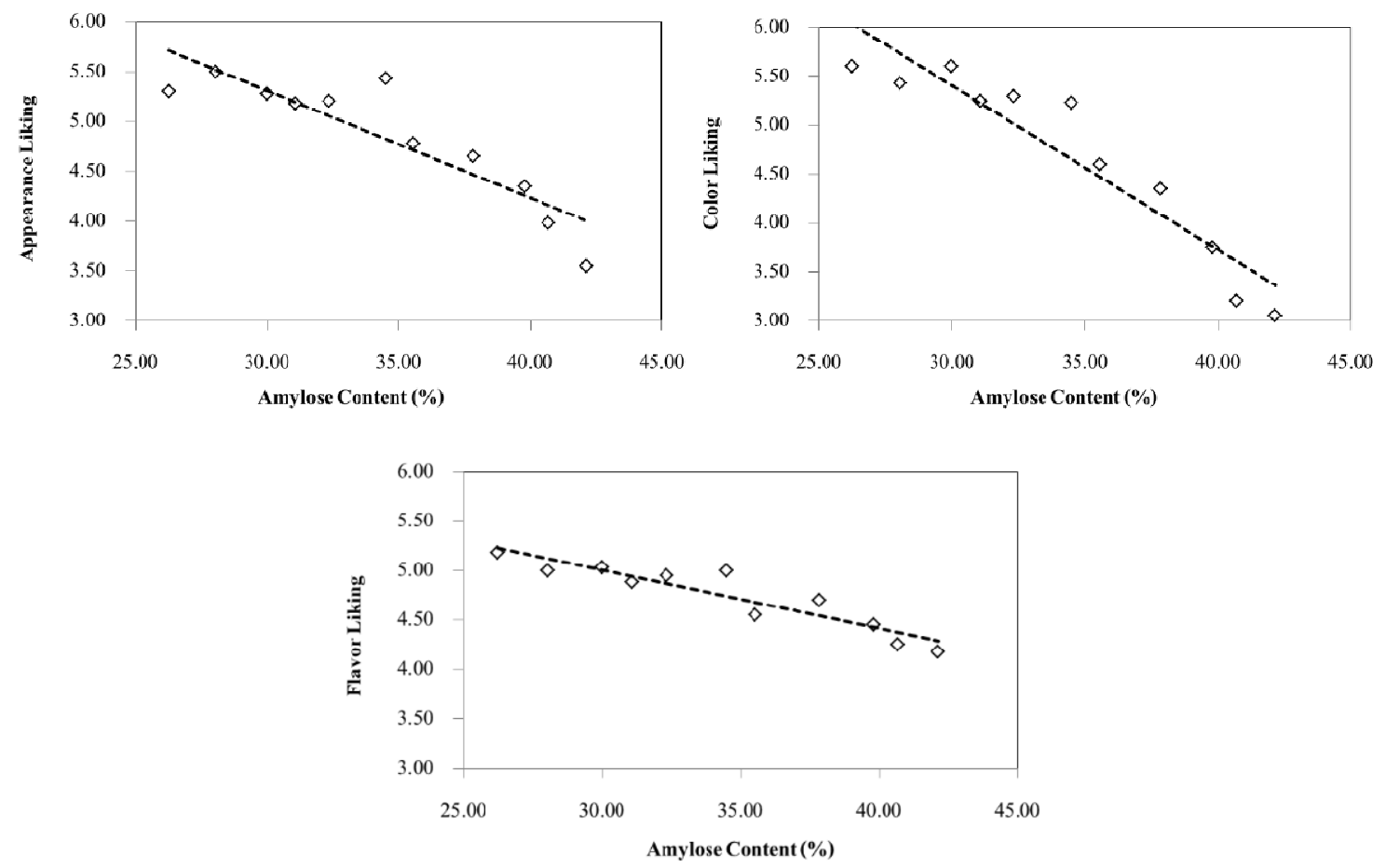

Figure 7 Correlation between amylose content and consumer acceptance.

\section{Conclusions}

Fried battered food are produced at home and in industries. Recently, they have become popular due to facility of frozen product for instant consumption. Moreover, since the jackfruit seed contains a starch, and the utilization of jackfruit seed is not yet significant and a half of the jackfruit seed becomes wastes. Therefore, this research aimed to develop a batter coating from JS. This study investigated the use of 
varying degrees of JS content in a batter coating mixture with respect to both the structural qualities and consumer preference evaluation as a frying batter. The amylose content of $40-41 \%$ JS was found to be suitable as batter coating for deep-fried products. This research shows the correlation between amylose content/relative crystallinity of the starch mixture and sensory attributes as well as consumer acceptance. Adding JS increased amylose content and relative crystallinity in the starch mixture, thus causing more crispness and less oil absorption, oiliness, and oil coating of the final product. A ratio of 50:50 WF:JS gave the highest score in consumer acceptance. This research could be of benefit to the development of various types of batter for deep-fried products.

\section{Acknowledgements}

The authors would like to thank Srinakharinwirot University for financial support through a research scholarship.

\section{References}

[1] MS Madruga, FS de Albuquerque, IR Silva, DS do Amaral, M Magnani and V Queiroga Neto. Chemical, morphological and functional properties of Brazilian jackfruit (Artocarpus heterophyllus L.) seeds starch. Food. Chem. 2014; 143, 440-5.

[2] K Rengsutthi and S Charoenrein. Physico-chemical properties of jackfruit seed starch (Artocarpus heterophyllus) and its application as a thickener and stabilizer in chilli sauce. LWT Food Sci. Tech. 2011; 44, 1309-13.

[3] V Tulyathan, K Tananuwong, P Songjinda and N Jaiboon. Some physicochemical properties of jackfruit (Artocarpus heterophyllus Lam) seed flour and starch. ScienceAsia 2002; 28, 37-41.

[4] T Gebre-Mariam and PC Schmidt. Isolation and physicochemical properties of Enset starch. Starch/Starke 1996; 48, 208-14.

[5] DA Alabi, OR Akinsulire and MA Sanyanyalolu. Quantitative determination of chemical and nutritional composition of Parkia biglobosa (Jacq.) Benth. Afr. J. Biotechnol. 2005; 4, 812-5.

[6] SM Fiszman and A Salvador. Recent developments in coating batters. Trends Food. Sci. Tech. 2003; 14, 399-407.

[7] MM Martínez, T Sanz and M Gomez. Influence of wheat flour subjected to different extrusion conditions on the rheological behaviour and thermal properties of batter systems for coating. $L W T$ Food Sci. Tech. 2015; 64, 1309-14.

[8] R Jiamjariyatam, V Kongpensook and P Pradiprasena. Effects of amylose content, cooling rate and aging time on properties and characteristics of rice starch gels and puffed products. J. Cereal. Sci. 2015; 61, 16-25.

[9] CG Oates and AD Powell. Bioavailability of carbohydrate material stored in tropical fruit seeds. Food Chem. 1996; 56, 405-14.

[10] Y Zhang, K Zhu, S He, L Tan and X Kong. Characterizations of high purity starches isolated from five different jackfruit cultivars. Food Hydrocolloid 2016; 52, 785-94.

[11] OS Kittipongpatana and N Kittipongpatana. Preparation and physicochemical properties of modified jackfruit starches. LWT Food. Sci. Tech. 2011; 44, 1766-73.

[12] H Dutta, SK Paul, D Kalita and CL Mahanta. Effect of acid concentration and treatment time on acid-alcohol modified jackfruit seed starch properties. Food. Chem. 2011; 128, 284-91.

[13] CL Mahanta and D Kalita. Processing and Impact on Active Components in Food. In: V Preedy (ed.). Processing and Utilization of Jackfruit Seeds. Tezpur University, Assam, India. 2015, p. 395400. 
http://wjst.wu.ac.th

[14] MH Gamble, P Rice and JD Selman. Relationship between oil uptake and moisture loss during frying potato slices from CV record UK tubers. Int. J. Food. Sci. Tech. 1987; 22, 233-41.

[15] IS Saguy and EJ Pinthus. Oil uptake during deep-fat frying-factors and mechanism. Food Tech. $1995 ; 49,142-5$.

[16] CR Southern, XD Chen, MM Farid, B Howard and L Eyres. Determining internal oil uptake and water content of fried thin potato crisps. Food Bioprod. Process. 2000; 78, 119-25.

[17] MB Roger. Functionality of Corn in Food Coatings. In: K Kulp and R Loewe (eds.). Batter and Breadings in Food Processing. American Association of Cereal Chemists, St. Paul, Minnesota, 1990, p. 29-49.

[18] W Yokoyama. Nutritional Properties of Rice and Rice Bran. American Association of Cereal Chemists, St. Paul, Minnesota, 2004, p. 595-609.

[19] SF Dogan, S Sahin and G Sumnu. Effects of soy and rice flour addition on batter rheology and quality of deep-fat fried chicken nuggets. J. Food. Eng. 2005; 71, 127-32.

[20] FF Shi and KW Daigle. Oil uptake properties of fried batters from rice flour. J. Agri. Food. Chem. 1999; 47, 1611-5.

[21] SF Dogan, S Sahin and G Sumnu. Effects of batters containing different protein types on the quality of deep-fat fried chicken nuggets. Eur. Food. Res. Tech. 2005; 220, 502-8.

[22] S Lee and GE Inglett. Functional characterization of steam jet-cooked-glucan rich barley flour as an oil barrier in frying batters. J. Food. Sci. 2006; 71, 308-13.

[23] A Mukprasirt, TJ Herald, DL Boyle and KD Rausch. Adhesion of rice flour based batter to chicken drumsticks evaluated by laser scanning confocal microscopy and texture analysis. Poult. Sci. 2000; 79, 1356-63.

[24] E Llorca, I Hernando, I Perez-Munuera, SM Fiszman and MA Lluch. Effect of frying on the microstructure of frozen battered squid rings. Eur. Food. Res. Tech. 2001; 213, 448-55.

[25] P Prabhasankar, D Indrani, J Rajiv and GV Rao. Scanning electron microscopic and electrophoretic studies of the baking process of south Indian parotta-an unleavened flat bread. Food Chem. 2003; 82, 603-9.

[26] JM Aguilera, L Cadoche, C Lopez and G Gutierrez. Microstructural changes of potato cells and starch granules heated in oil. Food. Res. Int. 2001; 34, 939-47.

[27] KK Bhat and S Bhattacharya. Deep fat frying characteristics of chickpea flour suspensions. Int. J. Food. Sci. Tech. 2001; 36, 499-507.

[28] BK Kim, JS Lee, CH Lee and DJ Park. Preparation of low-fat uptake frying batter composite by dry particle coating of microparticulated soybean hull. LWT Food. Sci. Tech. 2008; 41, 34-41.

[29] R Loewe. Ingredient Selection for Batter Systems. In: K Kulp and R Loewe (eds.). Batter and Breadings in Food Processing. American Association of Cereal Chemists, St. Paul, Minnesota, 1990, p. 11-28.

[30] FO Bobbio, AA El-Dash, PA Bobbio and LR Rodrigues. Isolation and characterization of the physicochemical properties of the starch of jackfruit seeds (Artocarpus heterorphyllus). Cereal. Chem. 1978; 55, 505-11.

[31] J Singh and N Singh. Studies on the morphological, thermal and rheological properties of starch separated from some Indian potato cultivars. Food Chem. 2001; 75, 67-77.

[32] AOAC. Official Methods of Analysis. Association of Official Analytical Chemists, Washington DC, 2005. 
http://wjst.wu.ac.th

[33] C Primo-Martin, NH van Nieuwenhuijzen, RJ Hamer and T van Vliet. Crystallinity changes in wheat starch during the bread-making process: Starch crystallinity in the bread crust. J. Cereal Sci. 2007; 45, 219-26.

[34] AOAC. Official Methods of Analysis. Association of Official Analytical Chemists, Washington DC, 1990.

[35] T Tondang. Some properties of starch extracted from three aromatic food seeds. Starch/Starke 2008; 60, 199-207.

[36] G Zhang, M Venkatachalam and BR Hamaker. Structural basis for the slow digestion of native cereal starches. Biomacromolecule 2006; 7, 3259-66.

[37] H Gao, J Cai, W Han, H Huai, Y Chen and C Wei. Comparison of starches isolated from three different Trapa species. Food Hydrocolloid 2014; 37, 174-81.

[38] Y Zhang, W Liu, C Liu, S Luo, T Li and Y Liu. Retrogradation behaviour of high-amylose rice starch prepared by improved extrusion cooking technology. Food Chem. 2014; 158, 255-61.

[39] DL Madrigal-Aldana, B Tovar-Gomez, M Mata-Montes de Oca, SG Sayago-Ayerdi, F GutierrezMeraz and LA Bello-Perez. Isolation and characterization of Mexican jackfruit (Artocarpus heterophyllus L) seeds starch in two mature stages. Starch/Starke 2011; 63, 364-72.

[40] B Altunakar, S Sahin and G Sumnu. Functionality of batters containing different gums for deep fat frying of carrot slices. J. Food. Eng. 2004; 75, 522-8.

[41] E Llorca, I Hernando, I Perez-Munuera, A Quiles, V Larrea and MA Lluch. The structure of starch granules in fried battered products. Food Hydrocolloid 2007; 21, 1407-12. 